\title{
Discussion on soft soil foundation treatment technology in municipal road and bridge engineering
}

\author{
Xiuyong $\mathrm{Ni}^{1 *}$ \\ SHANDONG TRANSPORT VACATIONAL COLLEGE, 271000, TAIAN, SHANDONG, CHINA
}

\begin{abstract}
Municipal road and bridge engineering is an important part of the transportation road construction in the city. Its construction quality directly affects the transportation quality and driving safety of the whole municipal road traffic. Among them, the foundation engineering of municipal road and bridge engineering is the main construction link. In the current municipal road and bridge construction process, it is often affected by many factors, leading to the reduction of the construction quality of municipal road and bridge engineering, especially the construction treatment of soft soil foundation in the foundation engineering, which is the main factor directly affecting the construction quality of municipal road and bridge. This paper first introduces the definition and relevant characteristics of soft soil foundation in the construction of municipal road and bridge engineering, and expounds the influence of soft soil foundation on municipal road and bridge engineering, and then analyzes the application of soft soil foundation treatment technology combined with the basic treatment ideas of soft soil foundation in the construction of municipal road and bridge.
\end{abstract}

\section{Introduction}

With social development and economic progress, the process of urbanization construction in China is speeding up, and its construction scale is also expanding. Municipal road and bridge engineering is an important part of urban traffic road. With the increasing number of municipal road and bridge engineering projects in the city, the construction and design of municipal road and bridge engineering also put forward more challenges and construction difficulties. The construction quality of municipal road and bridge engineering directly affects the image of the city and the daily travel quality of residents. In the construction of municipal road and bridge engineering, soft soil foundation is a common phenomenon, which brings a lot of problems for the construction of the whole engineering. In order to ensure the construction quality of municipal engineering projects, improve the level of urban traffic and road transportation, and enhance the safety and smoothness of residents' travel, it is necessary to focus on the research and practical application of soft soil foundation treatment technology.

\section{Definition and characteristics of soft soil foundation in municipal road and bridge engineering construction}

\subsection{Definition of soft soil foundation in municipal}

\section{road and bridge engineering construction}

Soft soil foundation mainly refers to the soil foundation conditions composed of soft soil with more fine particles and organic soil with larger gap, because the soil texture contains mucky soil, in which fine particles are composed of silt and other high compressibility soil with clay component or silt component. The definition of soft soil foundation is mainly derived from the change of foundation soil conditions caused by geographical conditions, geological structures and the characteristics and properties of soil conditions.

\subsection{Characteristics of soft soil foundation in municipal road and bridge engineering construction}

According to its main soil properties, the characteristics of soft soil foundation mainly include poor water permeability, high water content of soft soil, but relatively poor water permeability, extremely low shear strength, etc. Once the force of external load is transmitted to the foundation part, the shear foot brake and compression system with high compressibility or mucky soil usually show large settlement, which makes the projects such as buildings or roads and bridges built on the soft soil foundation have serious inclination or settlement, as shown in Diagram1:

\footnotetext{
*Xiuyong Ni: 704423842@qq.com
} 


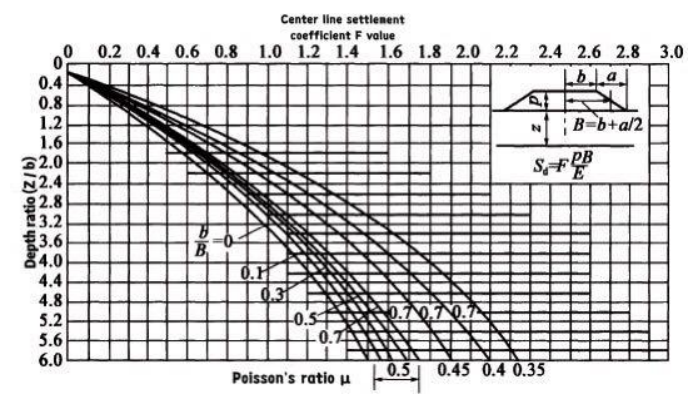

Diagram 1 Illustration of settlement coefficient in the central line of soft soil foundation

It is very easy to cause the damage and crack of the building and the increase of the macro pore, which will lead to the overall collapse of the building when it is serious. The soft soil foundation is similar to the related topography soil of river beach, valley bottom, lake marsh and seashore, or it is formed by the settlement of river beach, valley bottom, lake marsh and seashore, and the water content in the soil is relatively large. This makes the overall consolidation coefficient relatively lower, the consolidation time will be prolonged, and the disturbance is also great ${ }^{[1]}$. Therefore, the municipal construction units must actively analyze and study the soft soil foundation treatment, scientifically detect and test the shear resistance and load resistance level of the soft soil foundation.

\section{Influence of soft soil foundation on municipal road and bridge engineering construction}

\subsection{Poor bearing capacity of soft soil foundation}

In the construction of municipal road and bridge engineering project, it is very easy to be affected by soft soil foundation, which will seriously threaten the safety and reliability of municipal road and bridge engineering project construction and the driving safety after putting into use, even cause the collapse and damage of the road and bridge engineering project. It will cause serious financial loss and threaten people's life and property. In the case of soft soil foundation, the bearing strength of the foundation is relatively low due to the excessive water content and small seepage of the soil conditions, which is very easy to cause the settlement of municipal road and bridge engineering projects, and even cause the collapse of municipal bridges, which seriously threatens the travel quality of citizens and the stability of roads and bridges ${ }^{[2]}$.

\subsection{Large settlement of soft soil foundation}

One of the characteristics of soft soil foundation is the large settlement. In the construction of municipal road and bridge engineering projects, the actual soft soil foundation area encountered belongs to loose soil texture, which makes its bearing capacity extremely reduced, and the settlement caused by large gap and loose soft soil foundation will cause cracks in municipal road and bridge engineering projects, as shown in Fig. 2:

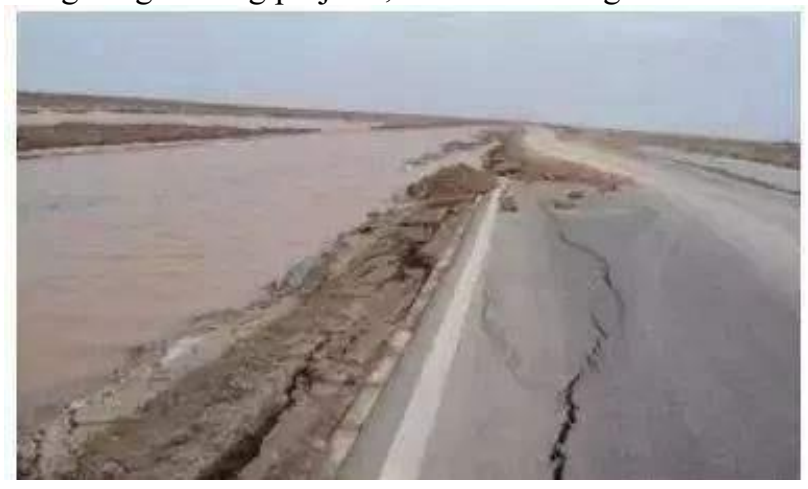

Fig. 2 Highway crack in soft soil foundation

In particular, municipal bridge projects with large self-weight and high height will incline due to weight and settlement, which is very easy to cause major safety accidents of road and bridge. In addition, the settlement characteristics of soft soil foundation will increase more difficulties and challenges for the subsequent construction of municipal road and bridge engineering projects, which will seriously affect and threaten the construction progress and quality of municipal road and bridge engineering projects.

\subsection{Strong compressibility of soft soil foundation}

In essence, the compressibility of soft soil foundation is strong, which is caused by the macro pore structure based on water content and soil quality. Especially in the construction of municipal road and bridge project, it is very easy to be affected by the soil layer of the macro pore soft soil foundation. During the construction, it is threatened by the soft soil layer of the macro pore, which makes it impossible to take effective control measures, and further affects the construction efficiency and progress of the municipal road and bridge, as well as the stability of the foundation and the bearing level of the road and bridge gravity. The result is easy to lead to the dislocation of the slope and the collapse of the subgrade of the municipal road and bridge engineering construction.

\section{Basic thoughts of soft soil foundation treatment in municipal road and bridge construction}

\subsection{Comprehensive consideration combined with environmental characteristics and soil characteristics}

In order to realize the effective treatment of the soft soil foundation in the construction of municipal road and bridge projects, the basic thoughts should be determined first in combination with the environmental characteristics and soil characteristics of the site. There are great differences in soil texture characteristics and 
soil characteristics in different regions, so there are also great differences in the selection of soft soil foundation treatment technology, which must be combined with the actual situation of soft soil foundation in municipal road construction for scientific inspection and detection. For example, if the nature of soft soil foundation belongs to clay characteristics, compaction technology can be selected as the main technology, and the disturbance to the foundation during construction can be minimized to maintain the integrity of the foundation ${ }^{[3]}$. The sand drawings with large gaps can be compacted by physical treatment technology with extrusion technology as an effective solution to ensure the bearing capacity of soft soil foundation, and the sand loading, vibration compaction and other technologies can be used to improve the mobility of soft soil foundation. At the same time, according to the depth and thickness of the soft soil foundation, we can choose the right treatment method, adopt the surface treatment technology or the replacement fill soil technology to deal with the soft soil foundation, and improve the consolidation level.

\subsection{Considering according to the specific design requirements of urban municipal roads}

In the construction of municipal roads, the requirements for roads are different, and the requirements for stability and balance are also different. For municipal engineering construction projects with higher grade, it is necessary to select strong soft soil foundation treatment technology to reduce the settlement as much as possible. For lower grade engineering, it is also necessary to adopt loading technology to carry out the construction after the settlement. If it is only a simple settlement treatment of the road surface, we can choose the treatment method of the soft soil foundation in the conventional pavement for the application of the replacement fill soil treatment technology. Choose different treatment methods according to the road shape, and the design width and height will also affect the technical level of soft soil foundation treatment. However, if the design is difficult or the road is not stable enough, the measures of loading should be considered and applied to enhance the bearing capacity of the foundation.

\subsection{Analysis on synthesizing the actual situation of the surrounding areas of municipal transportation}

The construction of municipal road and bridge engineering projects will also have a greater impact on the surrounding buildings. In particular, the vibration and noise generated in the construction process, as well as the underground water environment, urban pipeline laying and environmental pollution and other factors need to be considered in the treatment of construction technology ${ }^{[3]}$. Therefore, in the selection of soft soil foundation treatment technology, it is necessary to consider the surrounding environmental factors of the whole project construction, especially the building near the embankment toe of the road and bridge and the analysis of the overall soft soil foundation settlement, so as to ensure the stability and safety of the surrounding buildings and not affect the smooth passage of the municipal road and bridge engineering project.

\section{Application analysis of soft soil foundation treatment technology in municipal road and bridge construction}

\subsection{Powder jet pile reinforcement technology of soft soil foundation treatment technology}

Powder jet pile reinforcement technology is mainly aimed at some soft soil foundation with poor stability. During the construction process of municipal road and bridge engineering project, before the formal construction, it is necessary to conduct scientific field survey on the soft soil foundation, construction environment and surrounding soil characteristics of the construction site, and collect and analyze relevant data ${ }^{[4]}$. On the basis of this, the project design of municipal road and bridge engineering and the reasonable selection of soft soil foundation treatment technology are carried out. In the process of construction, it is necessary to control the depth of the lower part of the drilling machine and the elevation of the powder injection accurately to ensure that the powder injection is within the specified range. Before and after the use of the drill, it is necessary to carefully check and study the drill bit to ensure that the wear degree of the drill bit is kept within two centimeters, so as to realize the application quality of the soft soil foundation treatment technology of powder jet pile.

\subsection{Soft soil replacement filling technology of soft soil foundation treatment technology}

In the construction process of municipal road and bridge engineering projects, the soil replacement filling method for soft soil foundation soil is the most commonly used technical method in the current construction process. Its principle is very simple, which mainly refers to the replacement of the original soft soil with strong performance and strength to improve the bearing capacity and consolidation strength of the foundation. To adopt the soil replacement filling method, we must pay attention to the characteristics and properties of the soil, ensure that the selected soil has high strength and bearing capacity, and realize the effective treatment of the soft soil foundation, and select the soil with high stability and small compressibility. During replacement filling, it is also necessary to roll the foundation layer by layer to ensure that the maximum level can improve the compactness of the foundation and reduce the probability of settlement ${ }^{[5]}$.

\subsection{Surface drainage treatment technology of soft soil foundation treatment technology}

Surface drainage treatment technology mainly refers to one of the important technical means that can effectively 
improve the consolidation and stability of soft soil foundation. Its principle is to lay sand cushion on the soft soil foundation, and improve the high water content characteristics of the soft soil foundation on this basis. By using surface drainage treatment technology, the bearing capacity and bearing strength of the foundation can be improved on the premise of reducing the water content of the soft soil foundation, the passage of construction equipment and machinery can be realized, and some materials with better water permeability, such as gravel or gravel, can be used for trench backfilling to ensure the role of the trench. It can also realize the smooth construction of municipal road and bridge engineering projects and the guarantee of construction quality.

\subsection{Gravity dynamic compaction technology of soft soil foundation treatment technology}

In the soft soil foundation treatment technology, the use of physical gravity dynamic compaction technology is mainly aimed at the soft soil with large gap in the soft soil foundation. Its main technical principle is to repeatedly compact and compact the soft soil foundation with the help of the gravity effect in physics and the strong physical power generated by the falling of heavy objects in the high altitude. During the whole compaction process, the soil gap in the soft soil foundation can be reduced with the help of strong physical gravity to reduce the compressibility of the soft soil foundation, and then the overall strength and bearing capacity of the soft soil foundation can be increased ${ }^{[6]}$.

\section{Case study}

The municipal road and bridge construction project of the traffic road of the main road in the old city area of the southeast of Taicheng, East section of Lingshan street, Tai'an City, Shandong Province, which crosses the Shuxi River and connects the east of the city, is the key project of the municipal urban construction of the municipal Party committee and the municipal government. It is located on both sides of the Shuxi River, the overall construction site environment is more complex. As it is close to the river beach, the soil structure of the construction site belongs to soft soil foundation, and the whole municipal road and bridge construction project is close to the old residential quarters and old factory facilities. The construction environment is relatively concentrated, and the road status quo is full of cracks, which belongs to the traffic road situation of the old urban area. The moderate road project to be built is the reconstruction of the old urban area and the construction of the new municipal road and bridge engineering on the basis of the two-way two lane narrow road. The traffic road construction of the whole municipal road and bridge engineering is the east section of Lingshan street. It starts from Wenquan road in the west, passes through Shuxi River, Garden Road, Tangzhuang River, Shuanglong River, Tianzhufeng Road, Taixin railway, and ends at Panhe street in the east. As the East-West urban main road of Taicheng, the original foundation of the whole engineering pavement is $12 \mathrm{~m}$ wide cement pavement, which cannot meet the demand of urban vehicle transportation at this stage. The main difficulty of the engineering lies in the fact that the soft area, residential quarters and relevant old factory buildings are relatively dense, and the overall regional construction conditions are poor. Through the high attention of the municipal Party committee and the municipal government and the determination of the project by the construction unit and the supervision unit, the land acquisition and demolition work has been carried out, and the construction environment and conditions of the pavement construction of the road reconstruction engineering have been improved reasonably. According to the investigation of the soft soil foundation and the field underground pipeline, the foundation design of the municipal bridge engineering project and the road grass detection of some sections are completed. Combined with the actual survey data and soil conditions, the overall design scheme of the municipal road and bridge engineering project is established and the technical methods of the response soft soil foundation treatment are selected. After unremitting efforts, the municipal Housing and Urban Development Bureau and the municipal construction management unit actively carried out relevant technical research. The width of the red line of the road engineering in the design and construction section is about $60 \mathrm{~m}$, the green belt and sidewalk of the non-motor vehicle lane of the motor vehicle lane are set up, the two-way eight traffic lanes are designed, and the overall construction section is $3000 \mathrm{~m}$, which effectively solves the construction of the overall traffic facilities drainage, street lights, electricity and other related facilities, greatly alleviating the traffic pressure in the southeast of Taicheng.

According to the situation of soft soil foundation in the engineering construction, the Municipal Design Institute and the construction unit carried out joint investigation and research, made key analysis according to the geological conditions and environment of the actual construction site, carried out a reasonable construction design for the $2500 \mathrm{~m}$ construction road section belonging to the soft soil foundation, and taken targeted construction improvement measures according to the depth and scope of the soft soil foundation as well as the actual water content and strength. As shown in Fig. 3:

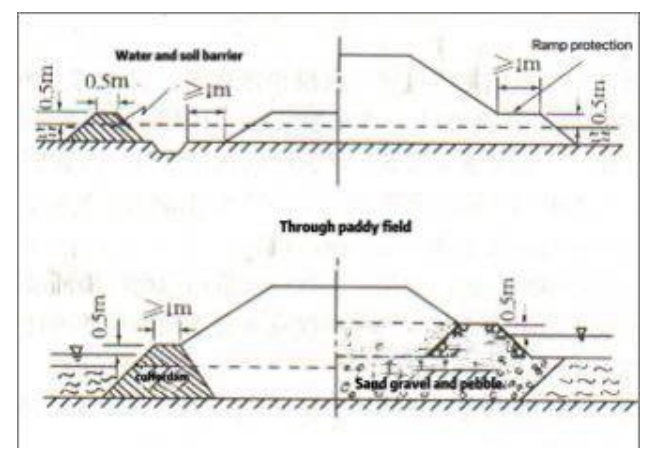

Fig. 3 Treatment design of adjacent water surface of soft soil foundation 
In particular, the embankment near the river carried out tamping treatment and replacement waterproof treatment, which enhances the strength of the subgrade part, and some parts close to 200 near the river are poured with concrete for finishing, so as to improve the load force of soft soil foundation and reach the construction standard.

\section{Concluding remarks}

Combined with the contents of the above article, municipal road and bridge project construction is an important part of urban traffic road project construction. In order to effectively solve the influence of soft soil foundation in the construction process of municipal road and bridge engineering, it is necessary to combine the actual geological conditions and soil structure characteristics of the construction site of municipal road and bridge, fully consider the design requirements of municipal road and bridge and the surrounding environmental factors, and take corresponding technical measures for the characteristics of soft soil foundation, such as large settlement, low bearing capacity and strong compressibility. Meet the actual design and construction requirements of urban municipal road and bridge construction projects, reduce the probability of potential safety hazards, improve the safety of residents' travel, promote the beautification degree of urban construction, and then realize the improvement of economic benefits and the embodiment of social values.

\section{Reference documents}

1. Lin Jiaxing. Discussion on the technical characteristics of soft ground foundation treatment in municipal road and bridge engineering construction [J]. Henan Building Materials,2019(03):224-225.

2. Li Linlin. Discussion on the technical characteristics of soft ground foundation treatment in municipal road and bridge engineering construction [J]. Henan Building Materials,2019(03):30-31.

3. Wang Tie, Xiao Lidong. Study on the Application of Soft Land Foundation Treatment Technology to the Construction of Municipal Road and Bridge Engineering [J]. New Technologies and Products in China,2019(03):105-106.

4. Wu Haibing. Research on soft ground foundation treatment technology in municipal road and bridge engineering construction [J]. Building Materials and Decoration,2019(01):282.

5. Wang xi. Analysis of soft ground foundation treatment technology in municipal road and bridge engineering construction $[\mathrm{J}]$. Housing and Real Estate,2018(33):199.

6. Tang Tianfei. Development analysis of soft ground foundation treatment technology in road and bridge engineering construction [J]. Residence,2018(33):40. 